Revista da Faculdade Mineira de Direito | v.21 N.41 31

\title{
REFORMA TRABALHISTA BRASILEIRA E O SUPREMO TRIBUNAL FEDERAL : AS ESCOLHAS TRÁGICAS?
}

BRAZILLAN LABOR REFORM AND THE SUPREME COURT : A TRAGIC CHOICE?

Aldacy Rachid Coutinho ${ }^{1}$

UFPR

\begin{abstract}
Resumo
O artigo analisa a reforma trabalhista brasileira de 2017 como uma escolha trágica que testemunha o domínio de uma racionalidade econômica da eficiência nas leis e nas decisões da mais alta Corte. Neste sentido, o Supremo Tribunal Federal vem sustentando a ideia de um novo modelo de Estado que se afasta do Welfare State para adotar uma forma de gestão mais flexível para a administração pública, o que se coaduna com a nova perspectiva regulatória do mercado de trabalho.
\end{abstract}

Palavras-chave

Direito do trabalho. Reforma. Eficiência. Administração pública.

\section{Abstract}

This article analyzes the Brazilian labor reform of 2017 as a tragic choice that testifies the domain of an economic rationality of efficiency in laws and High Court decisions. Thus, the Federal Supreme Court upholds the idea of a new state model that moves away from the Welfare State to adopt a more flexible form of management for public administration, which is in line with the new regulatory perspective of the labor market.

Keywords

Labour law. Reform. Efficiency. Public administration.

\section{Introdução}

${ }_{1}$ Professora Titular da Universidade Federal do Paraná. Especialista em Antropologia Filosófica pela UFPR. Aperfeiçoamento em Scienze Amministrative pela Università degli Studi di Roma. Mestre e Doutora pela UFPR. Procuradora do Estado do Paraná aposentada. Membro da Rede Nacional de Grupos de Pesquisa e Extensão em Direito do Trabalho e Seguridade Social - RENAPEDTS e Rede de Direito Público Brasil-EspanhaItalia - REDBRITES. 
Diz-se que a história se repete: primeiro como tragédia, depois como farsa. Desse modo pontuou Karl Marx (MARX, 1978, p.17) como presságio, ao escrever o 18 Brumário de Luis Bonaparte (Der 18te Brumaire des Louis Napoleon) entre dezembro de 1851 e março de 1852, referindo-se a dois momentos da história da França que desembocaram em golpes. $\mathrm{Na}$ data de 9 de novembro de 1799 - 18 brumaire an VIII, conforme o calendário francês -, Napoleão Bonaparte (Prince Archechancelier) toma o poder em França com um golpe de estado, via golpe militar, e institui o Consulado; após sua proclamação como primeiro-consul (1802) se torna imperador (1804), ou seja, consolida a ditadura já instaurada. Eis a marca do fim da Revolução Francesa.

Napoleão III, ou Louis Bonaparte, seguindo os trilhos históricos de seu tio, também por golpe de estado será imperador, após os momentos revolucionários de 1848 e 1851, representando a farsa da burguesia:

Hegel observa em uma de suas obras que todos os fatos e personagens de grande importância na história do mundo ocorrem, por assim dizer, duas vezes. E esqueceu-se de acrescentar: a primeira vez como tragédia, a segunda como farsa. ${ }^{2}$

É preciso pontuar e esclarecer, todavia, que em algumas versões da obra o verbo não é "repetir", mas “aparecer": (MARX, 1852)

Hegel remarks somewhere that all great worldhistoric facts and personages appear, so to speak, twice. He forgot to add: the first time as tragedy, the second time as farce." (grifo nosso)

Identificando as origens, tem-se que não obstante essa visão da história esteja também presente na Introdução à obra Crítica à filosofia do Direito de Hegel (MARX, 2010), a bem da verdade o apontamento parece ter origem na Carta de Engels para Marx (ENGELS, 1982) de 3 de dezembro de 1851, cujas ideias podem ser encontradas, em parte, também na obra 18 brumário de Luis Bonaparte: 
Revista da Faculdade Mineira de Direito | v.21 N.41 33

it really seems as though old Hegel, in the guise of the World Spirit, were directing history from the grave and, with the greatest conscientiousness, causing everything to be re-enacted twice over, once as grand tragedy and the second time as rotten farce, Caussidière for Danton, L. Blanc for Robespierre, Barthélemy for Saint-Just, Flocon for Carnot, and the moon-calf together with the first available dozen debt-encumbered lieutenants for the little corporal and his band of marshals. Thus the 18th Brumaire would already be upon us. (MIA)

Algumas outras possíveis fontes de referência ao pensamento do Hegel, poderiam ser A Filosofia do Direito_(HEGEL, 2010, \$347, p. 308) ou sobretudo, e mais precisamente, as Lecciones sobre la filosofia de la historia universal, no que tange o conceito de evolução: (HEGEL, 1989, p. 127):

La variación abstracta que se verifica en la historia ha sido concebida, desde hace mucho tempo, de un modo universal, como implicando un progresso hacia algo mejor y más perfecto. Las variaciones en la naturaliza, con ser tan infinitamente diversas como son, muestran solo un círculo, que se repite siempre. En la naturaliza no sucede nada nuevo bajo el sol [...]

Ou, então, quando Hegel analisa as fases da história, ao afirmar que "History is still predominantly unhistorical, for it is merely a repetition of the same majestic process of decline.” (HEGEL, 1975, p. 199)

Ademais, aponta Karl Marx para o papel dos homens como motor da história: fazem a própria história enquanto atores e, ao mesmo tempo, são feitos por ela:

Os homens fazem sua própria história, mas não a fazem como querem; não a fazem sob circunstâncias de sua escolha e sim sob aquelas com que se defrontam diretamente, legadas e transmitidas pelo passado. A tradição de todas as 
Revista da Faculdade Mineira de Direito | v.21 N.41 34

gerações mortas oprime como um pesadelo o cérebro dos vivos. (MARX, 1978, p. 17)

A reforma trabalhista que entrou em vigência em 11 de novembro de 2017 é a mais impactante expressão dessa tragédia resultado da história de homens; o legado e transmissão desse passado nos condena a enfrentar as circunstâncias opressoras, como pesadelo. Tomada como acontecimento terrível, é catástrofe anunciada sobre e para o futuro da classe trabalhadora, porquanto flexibiliza princípios de proteção e reduz direitos: eis a reforma!

Aristóteles, ao analisar a tragédia em Poética, prenunciou que ela, como imitação de uma ação, resulta em um momento de catarse do público, que por tal motivo a aprecia ao assistir o sofrimento dramatizado.

É pois a tragédia imitação de uma ação de caráter elevado, completa e de certa extensão, em linguagem ornamentada e com as várias espécies de ornamentos distribuídas pelas diversas partes [do drama], [imitação que se efetua] não por narrativa, mas mediante atores, e que, suscitando o 'terror e a piedade, tem por efeito a purificação dessas emoções. (ARISTÓTELES, 1991, p. 200-209)

Provoca ao mesmo tempo a compaixão e suscita o temor (terror e piedade), expurgando e purificando sentimentos, em movimento catártico. Contém heróis, deuses; envolve o destino. E, se está correto Aristóteles ao precisar que o "mito é o princípio e como que a alma da tragédia" (ARISTÓTELES, 1991, p. 207), esse mito se consubstancia hoje na "modernização".

Narrada em linguagem culta, eloquente, versando em pensamento - "poder dizer sobre tal assunto o que lhe é inerente e a esse convém" (ARISTÓTELES, 1991, p. 207) -, regulado pela política, aponta para um triste final, com sacrifícios ou destruição, ou dito de outra forma, esse espetáculo será a catástrofe. Mas sendo, ao mesmo tempo, farsa como catástrofe, se convola em teatro cômico de origem medieval, tendente à comédia de costumes, sem conflitos dramáticos, que mediante ação se apresenta por personagens com caricatura exagerada e atrapalhada do coditiano. Trata-se da encenação do engano dos tolos pelos espertos.

As questões postas em cena nesse espetáculo, diante da decisão de mudança da legislação trabalhista, devem ser analisadas a partir do 
enfrentamento de: (i) comportamento de indivíduos e instituições afetados pelos novos marcos regulatórios, sobretudo na Administração Pública; (ii) dos limites ao processo legislativo nas escolhas; (iii) da possibilidade de interferência do Poder Judiciário no controle de constitucionalidade diante de escolhas feitas pelos representantes do povo eleitos democraticamente.

As respostas podem ser apontadas a partir de uma abordagem econômica aberta ao jurídico no sentido de que (i) os indivíduos e instituições tomam decisões em tradeoffs e reagem a incentivos; (ii) os limites não se encontram na perspectiva de "escolhas trágicas", senão de escolhas; e (iii) a intervenção do Estado, pelo Poder Judiciário, é um imperativo (a) do regime democrático visando manter a ordem jurídica constitucional, inclusive para (b) a preservação do próprio sistema capitalista e do mercado nacional.

\section{A tragédia}

O anteprojeto de lei apresentado pelo Poder Executivo brasileiro para alteração da legislação trabalhista é encaminhado ao Congresso Nacional contendo apenas sete artigos; é devolvido para promulgação, após tramitação em processo legislativo, com mais de cem artigos e se torna a Lei 13.467, de 13 de julho de 2017. A decisão política sustenta-se naquela janela de oportunidades, dentre outras razões, em torno da necessidade de uma "modernização" da legislação trabalhista. Nas falácias das narrativas, justificativas várias capturaram o momento a partir do foco econômico e não jurídico; ou mais precisamente, do jurídico como econômico. Apontou para uma tragédia e inaugurou uma farsa; não concretizou um ótimo de Pareto.

A relação entre direito e economia abandonou a perspectiva que antes se cingia ao campo do direito concorrencial (anti-trust law), ou de um direito [capitalista] do trabalho, na simples, embora complexa, (inter)relação entre dois campos do saber. Na esteira dos estudos, sobretudo, de Guido Calabrese (Escola de New Haven) - um dos fundadores da Law and Economics ao lado de Ronald Coase - e, ainda no campo da análise econômica do direito, não obstante divergências com Richard Posner 
(Escola de Chicago) por conta de reflexões em termos de justiça e equidade diante da preocupação com a redistribuição, é imprescindível compreender os possíveis efeitos econômicos perversos provocados pelas decisões políticas legislativas. A questão central para a análise econômica do direito é a eficiência econômica ou, mais precisamente, a maximização da eficiência econômica das instituições sociais e, dentre estas, também do Direito (GALDINO, 2005, p. 242).

A análise econômica do direito entabulou questões de ordem jurídica aplicáveis para além do mercado e da intervenção estatal, sobretudo aos contratos e ao comportamento humano, investigando, por exemplo, como as ações das business firms podem gerar efeitos prejudiciais a terceiros, questionando evitar-se o prejuízo mais grave.

L'analisi economica del diritto assume come obiettivo la formazione de regole che garantiscano la realizzazione delle transazioni (cioè di quegli scambi e di quelle assegnazioni di risorse) che sono in grade di massimizzare il benessere complessivo. L'indicazione che essa fornisce è quella di preferire, tra le diverse possibili discipline di un certo fenomeno, quella che produce I risultati più efficienti (cioè, quella che massimizza il benessere complessivo) (DENOZZA, 2002, p.3)

$\mathrm{E}$, portanto, se as pessoas reagem a incentivos: contratar ou não contratar; e se os recursos são escassos: outsourcing com desemprego ou insourcing e criar novos postos de trabalho. As escolhas legislativas impactarão sempre, positiva ou negativamente, a eficiência do mercado.

Procedeu-se uma espécie de interpretação jurídica do Teorema de Coase, cuja expressão não é tributável a Ronald Coase (COASE, 2017, p. 157). Rejeitando o critério da primazia da maior utilidade apresentada pela escola econômica neoclássica, ele reconhece que o problema é recíproco, propondo que a adequada atribuição de direitos tornaria desnecessária uma intervenção estatal ou a aplicação de regras sancionatórias. Em uma transação econômica com externalidades, se os custos de transação são nulos ou suficientemente baixos em uma correta administração, e se os direitos de propriedade estão bem definidos, resultará uma alocação eficaz e a solução privada é socialmente ótima em um mundo fictício, chegando- 
se ao equilíbrio ótimo de Vilfredo Pareto. No mercado isso se traduziria no estado de recursos distribuídos de tal forma que diante de uma escolha que seria impossível aumentar sua utilidade realocando-os sem reduzir ou piorar a situação de outra pessoa. Neste caso, a intervenção do Estado não se faz necessária e, se ocorrer, representaria mais propriamente uma falha do mercado. O papel do Estado, aqui, ao invés de substituir-se à vontade dos contratantes, cinge-se a (i) garantir que os direitos de propriedade sejam bem definidos e (ii) que a livre negociação se mantenha sem (ou com baixos) custos de transação. Eis a lógica encetada pela reforma trabalhista.

Mas como não existe na realidade mundana ausência completa de custos de transação, os processos de mercado puros não se coadunam com a eficiência de Pareto. A intervenção, portanto, poderá ser justificada se e quando a ação produz benefícios superiores aos custos de transação, sem o qual engendraria uma perda.

O governo, para Coase, seria,

em certo sentido, uma super-firma (mas de um tipo muito especial), porquanto é capaz de interferir no uso dos fatores de produção por meio de decisões administrativas. Mas, a firma comum está sujeita a controles (checks) sobre suas operações tanto em razão da concorrência com outras firmas, as quais podem administrar as mesmas atividades a um custo menor, como, também, por haver sempre a alternativa das transações no mercado em vez da organização da firma, caso o custo administrativo se torne demasiadamente elevado. O governo é capaz, querendo, de evitar completamente o mercado, o que uma firma jamais poderá fazer. A firma tem de contratar com os detentores dos fatores de produção que utiliza. Assim como o governo pode limitar ou apoderar-se da propriedade, da mesma forma, pode ele decretar que os fatores de produção devem ser utilizados de determinada maneira. Tais métodos autoritários eliminam muitos problemas (para os responsáveis pela organização). Além disso, o governo pode 
Revista da Faculdade Mineira de Direito $\mid$ v.21 N.41 38

valer-se da polícia e de outros métodos coercitivos para assegurar que as regras por ele determinadas estejam sendo cumpridas. (COASE, 2009, p. 14)

O bem-estar, no mercado, passa a ser aferido em termos de alocações sociais para solução de problemas econômicos e jurídicos, projetados para todas as esferas da vida. Portanto, a lógica dos custos é introjetada como critério para tomada de decisão em comportamentos humanos. A eficiência, como consequência, passa a ditar a escolha.

\section{A farsa}

Farsa pode ser inferida no sentido de um comportamento ardiloso que introduz um engano. A reforma trabalhista brasileira encetada pela Lei 13.467, de 13 de julho de 2017, explicita o câmbio dessa racionalidade jurídica da legalidade por outra, agora identificada como uma racionalidade econômica da eficiência.

Sob o crivo de embates em torno das narrativas, argumentos falaciosos da necessidade emergente de mudanças na legislação trabalhista são apresentados como alavancas ao desenvolvimento econômico. Alardeia-se a notícia de que uma suposta e apontada "crise" no seio do capitalismo teria levado ao incremento do desemprego. Ao direito do trabalho, então, é imputada, falsamente, a causa da redução de postos de trabalho e da não admissão de novos empregados. Não por outra razão, o direito do trabalho não poderá ser a solução para questões econômicas.

É mister perceber, então, que as escolhas implicam sempre tradeoffs e geram consequências. Toda tomada de decisão, mesmo as que se apresentam como omissão ou inércia, pressupõe e exige uma comparação entre os custos e os benefícios a serem auferidos e outras possibilidades alternativas. Custo de oportunidade é, então, o que se desiste, ou seja, se abandona, se abre mão, ao se fazer uma opção. Desta forma, como os agentes no mercado reagem a incentivos, porquanto comparam os custos e os benefícios e assumem os tradeoffs, a proposta reformista foi apontada e acolhida como a única ou melhor resposta de enfrentamento; não há de se negar que se apresentou sempre como alguma escolha. Houve uma decisão 
Revista da Faculdade Mineira de Direito | v.21 N.41 39

tomada para alterar o marco regulatório laboral. E consequências certamente advirão, para todos.

Introduzir maior flexibilização na tomada da força de trabalho jamais fora um mecanismo útil (ou eficiente) para o combate ao desemprego ou para incrementar a renda de trabalhadores. A perspectiva de redução dos custos, na lógica de maximizar os resultados, igualmente prometeu a recuperação econômica mediante a redução de um equivocado "custo Brasil" (PASTORE, 1997) e de uma compensação da imaginária baixa produtividade da massa trabalhadora.

Entretanto, o resultado aponta, por um lado, a consolidação de uma proposta de Estado que já que vinha sendo delineada desde o Plano Diretor da Reforma do Aparelho do Estado (BRASIL, 2002) e que acarretou uma "revolução silenciosa" na gestão pública por uma pauta administrativa gerencial que almejava agilidade e eficiência e, de outra parte, para o acirramento da precarização e fragmentação das relações jurídicas que fora a marca do modelo brasileiro sobretudo desde a década de '70 do século passado, levando a um insignificante crescimento econômico e perda do poder aquisitivo da classe trabalhadora.

Justificou-se a reforma trabalhista como uma espécie de "escolha trágica" tal qual apresentada por Guido Calabresi e Philip Bobbit (CALABRESI; BOBBIT'T, 1978), mediante a qual as mudanças das regras jurídicas teriam sido decisões que visavam o atendimento de algumas necessidades em detrimento de outras. Exprimiu-se uma posição/teoria já chancelada pelo Supremo Tribunal Federal, ou seja, nada mais do que "estado de tensão dialética entre a necessidade de se tornar concretas e reais as ações e prestações [de saúde] em favor das pessoas, de um lado; e as dificuldades governamentais de viabilizar a alocação de recursos financeiros, sempre tão dramaticamente escassos, de outro" (STF, ARE 745.745, p. 9). E, portanto, no estabelecimento das prioridades, algumas escolhas podem ser trágicas, na medida em que gerariam prejuízos para alguns; no caso, mais precisamente, a alguns trabalhadores assalariados cujo vínculo seria estabelecido no modelo do trabalho assalariado (emprego). Ou, como não, para toda a classe trabalhadora.

Ocorre que o que se adotou fora o resultado do aproveitamento pelos políticos da porta aberta e escancarada para mudanças pontuais e específicas na legislação trabalhista, sem alteração do sistema ou do modelo 
de relações jurídicas. Fora um colapso doutrinário inicial; para além do desafio de reconstruir um direito do trabalho craquelado, o cenário aponta para a tentativa de empreender um projeto de sociedade de trabalho em substituição a uma proposta de sociedade salarial com rede de proteção social, legado do iluminismo, mediante promessas nunca cumpridas de modernidade.

Pode ser visto como uma alternativa para recursos escassos, sobretudo no ambiente público estatal. Pode ser aplaudido como introdutor de medidas de solução alternativas de conflitos, tais como mediação ou arbitragem. Pode ser tido como marco de uma nova civilidade pautada pelo negociado, acordado, conciliado.

Porém, as pessoas reagem a incentivos e a fuga do modelo do emprego acarretará certamente uma redução significativa de receitas públicas, inclusive tributárias, quer em decorrência do fenômeno da "pejotização", quer pela transformação do fato gerador da contribuição sindical para condicioná-la à vontade dos trabalhadores integrantes da categoria, quer pela facilitação de externalização da mão de obra, quer pelo decréscimo dos padrões remuneratórios, dentre outros.

O efeito backlash da reforma trabalhista será o acirramento da exclusão social. Com a diminuição do poder aquisitivo dos trabalhadores, gerando a piora das condições do capitalismo produtivo, haverá redução de padrões de demanda e, por consequência, de produção/oferta. O enfraquecimento dos movimentos de resistência e de luta, até pelo desalento, além da descrença na democracia e a percepção da inexistência de uma república, se traduzem em uma maior dificuldade de reverter efeitos negativos no futuro. A classe trabalhadora encontra-se fragmentada e precarizada.

Para compensar a diminuição da renda testemunharemos um endividamento crescente, impactando os orçamentos familiares e, com isso, se tornarão ainda mais vulneráveis as condições da cidadania para buscar efetivar o que resta de direitos.

Para assegurar os mesmos patamares de ingresso e renda os trabalhadores serão levados a aumentar a jornada de trabalho e intensificar a entrega de força de trabalho, fragilizando suas condições físicas e psicológicas, tendo como resultados certamente um aumento do adoecimento pelo/no trabalho, desestruturação familiar, dentre outros. 
Sem uma adequada rede de proteção social adequada e com a maior dificuldade em buscar no mercado o atendimento necessário, as conquistas civilizatórias de bem estar sofrerão um retrocesso histórico. Não há eficiência possível nesse cenário.

\section{As peças e o cenário}

A eficiência não é um elemento desconhecido do cenário do direito. A Constituição da República de 1988 prevê, sem seu "Art. 37. A administração pública direta e indireta de qualquer dos Poderes da União, dos Estados, do Distrito Federal e dos Municípios obedecerá aos princípios de legalidade, impessoalidade, moralidade, publicidade e eficiência e, também, ao seguinte: [...]." Trata-se de redação introduzida pela Emenda Constitucional 19/98, que [...] "alterou substancialmente a lógica de governança pública no Estado brasileiro. O que se percebe, desde o início, é que há uma dimensão ideológica que subjaz a proposta de inserção do princípio da eficiência à ordem constitucional vigente" (MARCELLINO JUNIOR, 2016, p. 38.)

Um primeiro olhar para a mudança constitucional permitiria inferir uma preocupação do poder constituinte derivado e voltado exclusivamente para uma natureza ética, visando melhor assegurar os resultados positivos para o bem da coletividade. Entretanto, um exame mais acurado leva a concluir que a emenda incorporou um câmbio epistemológico para acolher a ação eficiente (os fins justificam os meios) em substituição de uma eficácia (produção de efeitos finalísticos objetivados em uma relação causa-efeito). Eficácia e eficiência, por óbvio, são distintos significantes, que revelam diferentes paradigmas de atuação, ação, comportamento.

Salienta-se que a lógica da eficiência é absorvida no espaço estatal, público, convolando o cidadão em consumidor de serviços públicos: “[...] aumentar a eficiência dos serviços, atendendo melhor o cidadão-cliente a um custo menor" (BRASIL, 1995, p. 68) seria, por exemplo, um dos objetivos para o setor de serviços não exclusivos pautados por Organizações Sociais no Plano Diretor de Reforma do governo do Presidente Fernando Henrique Cardoso. 
O Supremo Tribunal Federal, desde muito, introduziu a eficiência como argumento e razão de decidir (obter dictum e ratio decidendi) em seus julgamentos, apontando inclusive para uma específica concepção de Estado e, igualmente, do interesse público e da atuação para prestação de serviços, muito mais próximas de uma racionalidade econômica. Desta forma, a reforma trabalhista e a Administração Pública situam-se nos marcos de mudanças mais amplas e já desde muito implementadas no campo do direito. Quiçá tenha sido o direito do trabalho o último baluarte de proteção de direitos fundamentais sociais atingido.

a) Já em 2007, o Supremo Tribunal Federal, ao apreciar a ADI 1864, ajuizada nos idos de 1998 pelo Partido dos Trabalhadores (PT) e pelo Conselho Nacional de Trabalhadores em Educação (CNTE), manteve incólume a Lei estadual 11.970, que em 1997 criou o Paranaeducação, pessoa jurídica de direito privado (ente autônomo de serviço social), para gestão do sistema educacional. O entendimento fora exarado no sentido de que a legislação estadual não conflitava com a ordem constitucional, assegurando interpretação conforme a Constituição aos dispositivos que regulavam a forma de gestão de recursos públicos no setor de educação (art. $3^{\circ}$, inc. I e art. 11, incisos IV e VII), "de sorte a entender-se que as normas de recursos financeiros a serem geridos pelo PARANAEDUCAÇÃO podem ter como objeto, unicamente, a parcela dos recursos forma $\mathrm{e}$ especificamente alocados ao PARANAEDUCAÇÃO, não abrangendo, em nenhuma hipótese, a totalidade dos recursos públicos destinados à educação no Estado do Paraná". (STF, ADI 1864, p. 91)

Particularmente interessantes foram, já à época, posições e visões de Estado ditadas pelo mito da modernidade. Neste diapasão merece destaque o voto do Min. Maurício Corrêa, relator:

É que o Estado moderno tem envidado todos os esforços para planejar políticas de curto, médio e longo prazo a fim de ajustar-se ao galopante crescimento da tecnologia nos diversos campos de sua atividade, como é a educação." (STF, ADI 1864, p. 102) [...] Não há negar que, modernamente, o Direito Público, conforme 
Revista da Faculdade Mineira de Direito | v.21 N.41 43

salienta Caio Tácito, levou a 'curva ascendente da expansão da ação direta do Estado na atividade econômica e social a seu ápice no início da década de $80[\ldots]$, e mais recentemente à 'expressiva valorização da iniciativa privada em áreas peculiares à inciativa estatal' . (STF, ADI 1864, p. 103)

Outrossim, o "pragmatismo da globalização e competitividade, de que se assenhorou a hodierna atividade humana” (STF, ADI 1864, p. 104) seriam imperativos para essa nova concepção de Estado, mediante a qual, a transferência de recursos públicos garantiria maior "eficiência e modernidade de seus serviços" (STF, ADI 1864, p. 119). A perspectiva da mudança do papel do Estado se situa como um imperativo dessa modernidade, no sentido de introduzir pautas de eficiência - sendo distinta e indiferente a eventual eficácia de seus outros princípios e regras:

Essas mudanças que o Estado sofreu no último quartel do século com marcas indeléveis no papel que desempenha perante a sociedade, foi bem retratada pelo publicista mexicano Miguel Acosta Romero, que antevê, em diversos países, entre os quais o Brasil, a constitucionalização dessas alterações, uma vez que 'vivem épocas de câmbio profundo, nos aspectos políticos, no papel que desempenha o Estado na sociedade do final do século vinte, de seu redimensionamento, da redefinição de prioridades e aspectos importantes da vida social, de formação de novos sistemas de Estados, de presença de interesses e forças reais de poder em nível nacional e internacional (empresas multinacionais ou transnacionais). A essa mudança política, física, geográfica e econômica correspondem também mutações constitucionais. (STF, ADI 1864, p. 103)

A eficiência já vinha apontada, por conseguinte, como razão de julgar. Afinal, "São todos serviços do Estado. O Estado busca cumprir sua função, valendo-se de instrumentos eficientes ou mais eficientes do que os 


\section{Revista da Faculdade Mineira de Direito | V.21 N.41 44}

dos órgãos públicos tradicionais. Há no sistema constitucional, alguma coisa que impeça isso?" questionou o Ministro Cezar Peluso em seu voto (STF, ADI 1864, p. 121).

Acompanhando a narrativa da eficiência, a flexibilização entra em cena no voto do Min. Joaquim Barbosa: "[...] como ente paraestatal, a maior flexibilização na gerência do PARANAEDUCAÇÃO, em razão também da incidência das normas de direito privado, leva a uma maior agilidade e eficiência na prestação do serviço ao qual está vinculado o instituto" (STF, ADI 1864, p. 136) Restou igualmente explícito no voto do Min. Gilmar Mendes que "[...] o que se busca aqui é [...] necessidade de algum mecanismo de flexibilização, algum mecanismo para estabelecer esta relação entre o modelo público ortodoxo e um outro modelo. Parece-me que esta é a tentativa e a própria interpretação conforme, proposta pelo eminente Ministro Joaquim Barbosa, que tenta fazer esta compatibilização" (STF, ADI 1864, p. 151).

Portanto, as palavras de ordem, modernização, eficiência (não obstante ser princípio constitucional) e flexibilização integram os enredos dos julgados. É o passado ditando o futuro na construção da historiografia trabalhista. A reforma não se consubstancia em um acontecimento isolado, mas se integra perfeitamente ao momento histórico.

b) Mais recentemente, o Supremo Tribunal Federal, em julgamento proferido em 16 de abril de 2015, apreciou na ADI 1923-DF (STF, ADI 1923) a questão da constitucionalidade da possibilidade de instituições privadas, denominadas Organizações Sociais, prestarem serviço público em atividades de ensino, pesquisa científica, desenvolvimento tecnológico, proteção e preservação do meio ambiente, cultura e saúde. Em síntese, como explicita a ementa:

1. A atuação da Corte Constitucional não pode traduzir forma de engessamento e de cristalização de um determinado modelo pré-concebido de Estado, impedindo que, nos limites constitucionalmente assegurados, as maiorias políticas prevalecentes no jogo democrático pluralista possam pôr em prática seus projetos de governo, moldando o perfil e o instrumental do 
Revista da Faculdade Mineira de Direito $\mid$ v.21 N.41 45

poder público conforme a vontade coletiva. [...] 7 . $\mathrm{Na}$ essência, preside a execução deste programa de ação institucional a lógica que prevaleceu no jogo democrático, de que a atuação privada pode ser mais eficiente do que a pública em determinados domínios, dada a agilidade e a flexibilidade que marcam o regime de direito privado. (STF, ADI 1923)

Como indicou a Min. Cármen Lúcia, nessa nova roupagem de Estado, mediante parcerias público-privadas '[...], o que se pretende, o que se buscou foi exatamente uma prestação mais eficiente, que é um dos princípios da Administração Pública” (STF, ADI 1923, p. 137). No mesmo trilhar seguiu a posição do Min. Gilmar Mendes, ao precisar "[...] que [o que] se cuida, basicamente, é de buscar um novo modelo de administração que possa, eventualmente, revelar-se mais eficiente do que aquele que se atinge na forma tradicional, mas sob os controles do próprio Estado." (STF, ADI 1923, p. 140)

Esse novo modelo de Estado pressupõe, seguindo a posição da mais alta Corte do Brasil, a organização de uma Administração Pública cuja gestão mais flexível, inclusive em torno de alocação de recursos financeiros, mesmo em se tratando de execução de políticas públicas e prática de atos administrativos, leve em conta a lógica da eficiência.

A eficiência é o filtro de apreciação dos direitos dos servidores públicos:

Inexiste violação aos direitos dos servidores públicos cedidos às organizações sociais, na medida em que preservado o paradigma com o cargo de origem, sendo desnecessária a previsão em lei para que verbas de natureza privada sejam pagas pelas organizações sociais, sob pena de afronta à própria lógica de eficiência e de flexibilidade que inspiraram a criação do novo modelo. (STF, ADI 1923, p. 7)

Nos seus esclarecimentos, o Min. Luiz Fux, lembra que o Min. Gilmar Mendes, ao tempo da análise da liminar, que aliás não fora deferida, teria destacado esse novo modelo de Administração Gerencial corolário de 
outra concepção, mais moderna, de Estado: “[...] é um projeto de reforma gerencial do Estado, nessa constatação inequívoca de que o Estado não consegue atingir as suas finalidades se não houver essa coparticipação nessa atividade coadjuvante. [...] Esse novo modelo de administração gerencial realizado por entidades públicas, ainda que não-estatais, está voltado mais para o alcance de metas do que para a estrita observância de procedimentos. A busca da eficiência dos resultados, por meio da flexibilização de procedimentos, justifica a implementação de um regime todo especial (STF, ADI 1923, p. 121-122).

Naquele tempo, a Min. Rosa Weber, em seu voto, explicitou sua posição contrária à ideia de efetividade com flexibilização como critério de atuação estatal, ressaltando que seria uma indevida "terceirização" que migraria da esfera trabalhista para a ambiente público:

Por outro lado, também não posso esquecer - até comentava há pouco - o que todos entendemos: que a Constituição é viva, a Constituição é aquilo que o Supremo diz que é, a interpretação que confere ao Texto Constitucional. Mas tenho enorme dificuldade, Senhor Presidente, de, nesse âmbito - perdoem-me, mas seria uma terceirização da própria atividade estatal, não mais a terceirização na órbita trabalhista, da ótica do trabalho, daquele que executa o trabalho, da atividade do trabalhador, mas da atividade estatal como tal [...]. (STF, ADI 1923, p. 134-135)

Entretanto, como a própria Min. Rosa Weber pugnou, a Constituição é viva, sendo ao fim e ao cabo o que o Supremo diz que é, por meio de interpretação constitucional. Por conseguinte, uma década mais tarde, a mesma corte, consoante acórdão redigido pelo Min. Luiz Fux, ao enfrentar o tema da responsabilidade subsidiária da Administração Pública (STF. RE 760931) assumiu na sua inteireza a racionalidade econômica da eficiência, inclusive tendo sido citado o pensamento de Ronald Coase:

A Administração Pública, pautada pelo dever de eficiência (art. 37, caput, da Constituição), deve empregar as soluções de mercado adequadas à prestação de serviços de excelência à população com 
Revista da Faculdade Mineira de Direito | v.21 N.41 47

os recursos disponíveis, mormente quando demonstrado, pela teoria e pela prática internacional, que a terceirização não importa precarização às condições dos trabalhadores. (STF. RE 760931)

A Corte Constitucional, deliberando em torno da Constitucionalidade do art. $71, \int 1^{\circ}$, da Lei $n^{\circ} 8.666 / 93$, tal qual já tinha sido reconhecida em caráter erga omnes e vinculante na ADC 16, de relatoria do Min. Cezar Peluso e julgado em 24 de novembro de 2010, houve por bem conhecer parcialmente o Recurso Extraordinário para, na parte admitida, julgá-lo procedente para fixar como tese para decidir casos semelhantes: "O inadimplemento dos encargos trabalhistas dos empregados do contratado não transfere automaticamente ao Poder Público contratante a responsabilidade pelo seu pagamento, seja em caráter solidário ou subsidiário, nos termos do art. 71, \ $1^{\circ}$, da Lei no 8.666/93".

Deste modo, o imperativo de eficiência, independentemente da correição do sentido a ela atribuída, é alçado a pensamento quase hegemônico:

1. A dicotomia entre "atividade-fim" e "atividademeio" é imprecisa, artificial e ignora a dinâmica da economia moderna, caracterizada pela especialização e divisão de tarefas com vistas à maior eficiência possível, de modo que frequentemente o produto ou serviço final comercializado por uma entidade comercial é fabricado ou prestado por agente distinto, sendo também comum a mutação constante do objeto social das empresas para atender a necessidades da sociedade, como revelam as mais valiosas empresas do mundo. É que a doutrina no campo econômico é uníssona no sentido de que as "Firmas mudaram o escopo de suas atividades, tipicamente reconcentrando em seus negócios principais e terceirizando muitas das atividades que previamente consideravam como centrais" (ROBERTS, John. The Modern Firm: 
Revista da Faculdade Mineira de Direito $\mid$ v.21 N.41 48

Organizational Design for Performance and Growth. Oxford: Oxford University Press, 2007). 2. A cisão de atividades entre pessoas jurídicas distintas não revela qualquer intuito fraudulento, consubstanciando estratégia, garantida pelos artigos $1^{\circ}, \mathrm{IV}$, e 170 da Constituição brasileira, de configuração das empresas, incorporada à Administração Pública por imperativo de eficiência (art. 37, caput, CRFB), para fazer frente às exigências dos consumidores e cidadãos em geral, justamente porque a perda de eficiência representa ameaça à sobrevivência da empresa e ao emprego dos trabalhadores. (STF. RE 760931)

Tanto as ratio decidendi quanto as obiter dictum, assim, foram acolhidas e são ditadas por argumentos administrativos e econômicos, como se depreende da própria Ementa; por todos, destacam-se as expressões próprias da economia e gestão na iniciativa privada, na busca de benefícios, tais como incentivos, precificação, custos, custos fixos, competição, desempenho, concorrentes, mercado, riscos, flexibilidade, além de, por óbvio, eficiência:

A terceirização apresenta os seguintes benefícios:

(i) aprimoramento de tarefas pelo aprendizado especializado; (ii) economias de escala e de escopo; (iii) redução da complexidade organizacional; (iv) redução de problemas de cálculo e atribuição, facilitando a provisão de incentivos mais fortes a empregados; (v) precificação mais precisa de custos e maior transparência; (vi) estímulo à competição de fornecedores externos; (vii) maior facilidade de adaptação a necessidades de modificações estruturais; (viii) eliminação de problemas de possíveis excessos de produção; (ix) maior eficiência pelo fim de subsídios cruzados entre departamentos com desempenhos diferentes; (x) redução dos custos iniciais de entrada no mercado, facilitando o surgimento de novos concorrentes; (xi) superação de eventuais limitações de acesso a 
Revista da Faculdade Mineira de Direito $\mid$ v.21 N.41 49

tecnologias ou matérias-primas; (xii) menor alavancagem operacional, diminuindo a exposição da companhia a riscos e oscilações de balanço, pela redução de seus custos fixos; (xiii) maior flexibilidade para adaptação ao mercado; (xiii) não comprometimento de recursos que poderiam ser utilizados em setores estratégicos; (xiv) diminuição da possibilidade de falhas de um setor se comunicarem a outros; e (xv) melhor adaptação a diferentes requerimentos de administração, knowhow e estrutura, para setores e atividades distintas. (STF. RE 760931)

Por fim, a lógica que gravita em torno do Estado e sua função, bem como da Administração Pública e sua gestão, é exatamente a determinada pela atuação do mercado. Não somente as razões de decidir são pautadas pela racionalidade econômica da eficiência, senão que o próprio Estado é identificado como uma firma. No voto, a Corte Constitucional traz o pensamento de Coase sobre a natureza da firma e processos de produção para o mercado, para apreciar uma matéria que envolve a atuação estatal e o espaço público.

Histórico científico: Ronald $\mathrm{H}$. Coase, "The Nature of The Firm", Economica (new series), Vol. 4, Issue 16, p. 386-405, 1937. O objetivo de uma organização empresarial é o de reproduzir a distribuição de fatores sob competição atomística dentro da firma, apenas fazendo sentido a produção de um bem ou serviço internamente em sua estrutura quando os custos disso não ultrapassarem os custos de obtenção perante terceiros no mercado, estes denominados "custos de transação", método segundo o qual firma e sociedade desfrutam de maior produção e menor desperdício. (STF. RE 760931)

Talvez o déficit de república no Brasil tenha em muito contribuído para a difícil e conturbada separação entre público e privado. E a 
Revista da Faculdade Mineira de Direito | v.21 N.41 50

terceirização, com implicações em torno da responsabilidade dos entes públicos, é apenas a ponta do iceberg.

\section{Para concluir...}

e para refletir: a reforma trabalhista não é um fato isolado na história brasileira contemporânea. Não é o algoz, senão mais um testemunho dessa transformação do Estado de bem-estar social que assume a lógica do mercado. Dessa forma, é possível compreender - embora não concordar ou aceitar - que venha a reforma conviver com uma Constituição cidadã. É que o texto constitucional vem sendo, por sucessivos processos hermenêuticos destruidores perpetrados inclusive e sobretudo pela pena do Supremo Tribunal Federal, sendo reescrita com a tinta da racionalidade econômica da eficiência.

A retirada do Estado interventor do mercado, do Estado garantidor de direitos, do Estado exercente de atividades típicas e centrais, porém, não será absoluta, total; não se está a caminho no imaginário de uma sociedade sem Estado; a função prioritária talvez será apenas o assistencialismo no âmbito social, para além da árdua tarefa de conter a violência daqueles que nada mais terão a perder e que não contam mais com a possibilidade de encontrar no direito a canalização dos seus anseios e desejos, para que então tenham que se defrontar com o que resta, um Estado policial.

Teria sido a reforma trabalhista brasileira introduzida pela Lei 13467/2017 uma escolha trágica?

A ideologia neoliberal introduziu uma mudança epistemológica mais profunda e mais nefasta do que apenas o fim do protagonismo do direito do trabalho: apontou para a tragédia das escolhas a serem suportadas por todos.

\section{Referências}


Revista da Faculdade Mineira de Direito $\mid$ v.21 N.41 $\mid 51$

ARISTÓTELES. Ética a Nicômaco; Poética. 4.ed. São Paulo : Nova cultural, 1991.

BRASIL. MINISTÉRIO DO PLANEJAMENTO, ORÇAMENTO E GESTÃO. Balanço da reforma do estado no Brasil: a nova gestão pública. Brasília : MP, SEGES, 2002. Disponível em: https://bvssp.icict.fiocruz.br/pdf/e0002010.pdf Acesso em: 20abr.2018

BRASIL. MINISTÉRIO DA ADMINISTRAÇÃO FEDERAL E REFORMA DO ESTADO. Plano diretor da reforma do aparelho do Estado. Presidente Fernando Henrique Cardoso, 1995. Disponível em: http://www.biblioteca.presidencia.gov.br/publicacoesoficiais/catalogo/fhc/plano-diretor-da-reforma-do-aparelho-do-estado1995.pdf Acesso em: 20abr.2018.

CALABRESI, Guido; BOBBITT, Philip. Tragic choices. New York : W.W. Norton \& company, 1978.

COASE, Ronald. O problema do custo social. The Latin American and Caribbean Journal of Legal Studies. Chicago, 2009. v.3, n.1, artigo 9, p. 1-36. Disponível em: http://services.bepress.com/lacjls/vol3/iss1/art9 Acesso em: 02abr.2018.

. A firma, o mercado e o direito. 2.ed. Rio de Janeiro : Forense universitária, 2017.

DENOZZA, Francesco. Norme efficienti: l'analisi economica delle regole giuridiche. Milano : Giuffrè editore, 2002.

ENGELS, Friedrich. MARXS-ENGELS correspondence 1851. Engels to Marx in London. Manchester, 3 December 1851. Collected Works (MECW). v. 38. 1844-1851. Londres : Ed. Lawrence \& Wishart, 1982. p. 503-506.

Disponível

em:

https://www.marxistsfr.org/archive/marx/works/1851/letters/51 1203 . htm Acesso em: 18abr.2018.

GALDINO, Flávio. Introdução à teoria dos custos dos direitos. Direitos não nascem em árvores. Rio de Janeiro : Lumen Juris, 2005. HEGEL, Georg Wilhelm Friedrich. Lectures on the filosophy of world history. Introduction: reason in history. Cambridge : Cambridge university press, $1975 . \quad$ Disponível em: https://books.google.com.br/books?id=pjfaimuprzoC\&printsec=frontco ver\&redir esc $=_{\mathrm{y}} \# \mathrm{v}=$ onepage $\& \mathrm{q}=$ repetition $\& \mathrm{f}=$ false Acesso em: $12 \mathrm{abr} .2018$ 
Revista da Faculdade Mineira de Direito | v.21 N.41 52

. Princípios da filosofia do direito. Lisboa : Martins Fontes, 1976. . Lecciones sobre la filosofia de la história universal. Madrid : Alianza editorial, 1989.

. Linhas fundamentais da filosofia do direito. São Leopoldo : Unisinos, 2010.

MARCELLINO JÚNIOR, Julio Cesar. Análise econômica do acesso à justiça: a tragédia dos custos e a questão do acesso inautêntico. Rio de Janeiro : Lumen Juris, 2016.

MARX, Karl. O 18 de brumário e Cartas a Kugelmann. 4. ed. Rio de Janeiro : Paz e Terra, 1978.

. The Eighteenth Brumaire of Louis Bonaparte. Karl Marx

1852. Disponível em:

https://www.marxists.org/archive/marx/works/1852/18th-

brumaire/ch01.htm Acesso em 2abr.2018.

. Crítica da filosofia do direito de Hegel, 1843. 2.ed. São Paulo : Boitempo, 2010.

MIA - Marxists Internet Archive. Encyclopedia of Marxism. History Repeats Itself? Disponível em https://www.marxists.org/glossary/terms/h/i.htm\#history-repeats Acesso em 2abr.2018

PASTORE, José. Encargos Sociais: implicações para o salário, emprego e competitividade. São Paulo : LTR, 1997.

STF. ADI 1864. Relator Min. Maurício Corrêa. Julgamento em 8ago.2007. Publicado em 2mai.2008. Acórdão.

STF. ADI 1923-DF. Redator para o acórdão Min. Luiz Fux. Relator Min. Ayres Brito. Julgamento em 16abr.2015. Publicado em 17dez.2015. Acórdão.

STF. ARE 745.745- MG. 2a . Turma. Relator Min. Celso de Mello. Julgamento em 2dez2014. Publicado em 19dez.2014.

STF. RE 760931. Relatora Min. Rosa Weber. Redator para o acórdão Min. Luiz Fux. Tribunal Pleno. Julgamento em 26abr.2017. Processo eletrônico Repercussão geral. Publicado em 12set. 2017. 